\title{
Entrapment of the Medial Branch of the Superior Cluneal Nerve - a Previously Unrecognized Cause of Lower Back Pain in Cricket Fast Bowlers
}

\author{
Simon Speed ${ }^{\mathrm{a}, \mathrm{d}}$, Kevin Sims ${ }^{\mathrm{b}}$, Patrick Weinrauch ${ }^{\mathrm{c}}$
}

\begin{abstract}
Cricket fast bowlers have a high incidence of injury and are prone to back problems that can become debilitating and foreshorten their careers. We present a case of superior cluneal nerve (SCN) entrapment neuropathy as a previously unrecognized etiology of lower back pain in a professional cricket fast bowler, often misdiagnosed as a lumbar spine disorder. We believe that the SCN may be susceptible to compression related to repetitive contraction of the back musculature, in particular the Thoraco-lumbar erector spinae (TLES) and Latissimus dorsi which contribute to a fibro-osseous tunnel through which the SCN runs. The problem can be readily treated with surgical decompression and patients can expect a return to near full function. Clinicians should be aware of this diagnosis when investigating athletes for chronic lower back pain.
\end{abstract}

Keywords: Superior cluneal nerve entrapment; Chronic lower back pain; Iliac crest pain; Cricket fast bowlers

\section{Introduction}

Cricket fast bowlers have a high incidence of injury and are especially prone to back problems. As a result they can miss $16 \%$ of all potential playing time during their careers, whereas players from other positions miss only $5 \%$ [1]. Individual bowler workload [2] and mechanics have been the most

Manuscript accepted for publication March 15, 2011

${ }^{a}$ Orthopedic Department, QEII Hospital, Brisbane, Australia

${ }^{\mathrm{b}}$ Cricket Australia Center of Excellence, Australia

${ }^{\mathrm{c}}$ Brisbane Hip Clinic, St Andrews War Memorial, Brisbane, Australia

${ }^{\mathrm{d}}$ Corresponding author: Simon Speed, simon.speed@bigpond.com

doi: $10.4021 / \mathrm{jmc} 167 \mathrm{w}$ studied risk factors for fast bowler injury [3]. A proportion of these injuries will go unrecognized and untreated despite modern investigations. Common problems include facet joint irritation, disc degeneration and iliolumbar syndrome [4]. We present a case of superior cluneal nerve (SCN) entrapment neuropathy as a previously unrecognized etiology of lower back pain in cricket fast bowlers, often misdiagnosed as a lumbar spine disorder. This problem can be treated with surgical decompression and patients can expect return to near full function.

The medial branch of the superior cluneal nerve innervates a fan shaped area of skin from the iliac crest, $7-8 \mathrm{~cm}$ from the midline [5]. The thoracolumbar and latissimus dorsi muscles attach to the dorsal rim of the posterior iliac crest and the medial branch of the superior cluneal nerve enters a fibro-osseous tunnel formed by these muscles and the bone above the level of the iliac crest [5]. The nerve travels in this tunnel before perforating the fascia $8 \mathrm{~cm}$ from the midline [5]. The medial branch can become irritated or entrapped in the fibro-osseous tunnel causing tenderness over the iliac crest and pain radiating in the distribution of the nerve [6]. The intermediate and lateral branches tend to pass through the fascia above the level of the iliac crest and are not routinely compressed as a result. There are limited case reports in the literature of this problem $[7,8]$.

\section{Case Report}

A 31-year-old professional cricketer playing at an elite level presented with a 5 month history of new onset left iliac crest and buttock discomfort superimposed on a background of generalized back problems for the preceding 12 month period. These problems had been very disruptive to his professional career and he had been unable to participate in elite cricket during this time. He presented with point tenderness over the left iliac crest $8 \mathrm{~cm}$ from the midline, and pain radiating in a fan shaped distribution inferior and lateral from this location. The pain was made worse by right arm fast bowling. He did not have symptoms distributed to the groin or thigh and his back was relatively pain free on presentation. 


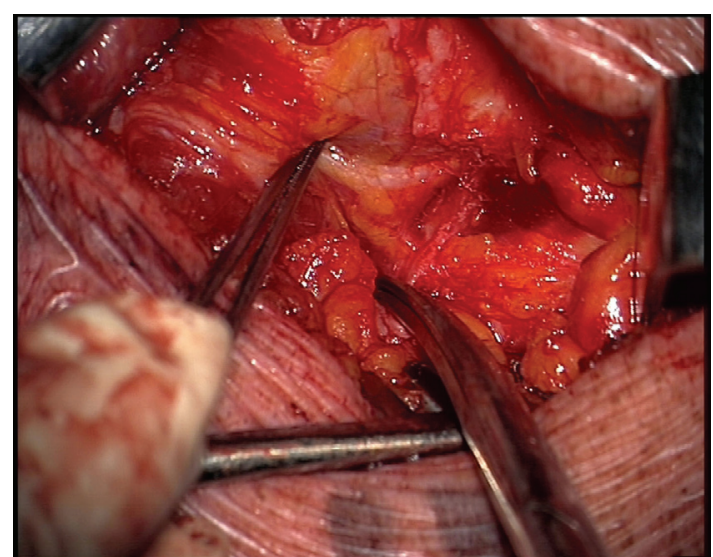

Figure 1. The medial branch of the superior cluneal nerve was identified and seen to emerge from beneath the fibroosseous fascia before bifurcating.

On examination, there was point tenderness to palpation of the iliac crest $8 \mathrm{~cm}$ from the midline. Range of motion of the lumbar spine was preserved. Range of motion of the hip throughout mid and terminal arc was pain free. The FABER test and quadrant sign were negative. A lower limb neurological examination of both motor and sensory was unremarkable. The subject noticed pain in the buttock region with deep squats.

MRI of the right hip did not demonstrate clear evidence of acetabular labral pathology. There was an incidental finding of a small cyst on the head neck junction of the proximal femur. Disc degeneration at L5/S1 was observed with a region of increased uptake on bone scan in the pedicle of L5 on the right side which had remained unchanged over many years and as was considered coincidental to his symptoms.

Infiltration of local anaesthetic Marcaine into the point of maximal tenderness to palpation $(8 \mathrm{~cm}$ laterally to the midline, $0.6 \mathrm{~cm}$ inferiorly to the iliac crest) on two separate occasions resulted in a clear improvement in symptoms with a pain-free interval. On this basis the diagnosis of SCN entrapment was confirmed.

The patient gave their informed consent to undergo surgical decompression.

The patient was administered a general anaesthetic and placed in the prone position. An operating microscope was used. Skin was marked over the operative site. An oblique incision was made, $8.5 \mathrm{~cm}$ from the midline at the level of the iliac crest. The medial branch of the superior cluneal nerve was identified tracking inferiorly to the crest and seen to emerge from beneath the fibro-osseous fascia before bifurcating (Fig. 1). Thoracolumbar fascia over the nerve was then identified and released (Fig. 2) and a fat graft placed over the nerve release site.

The patient recovered well and was able to return to cricket four weeks post surgical decompression. The perioperative bruising and post-surgical inflammation took six

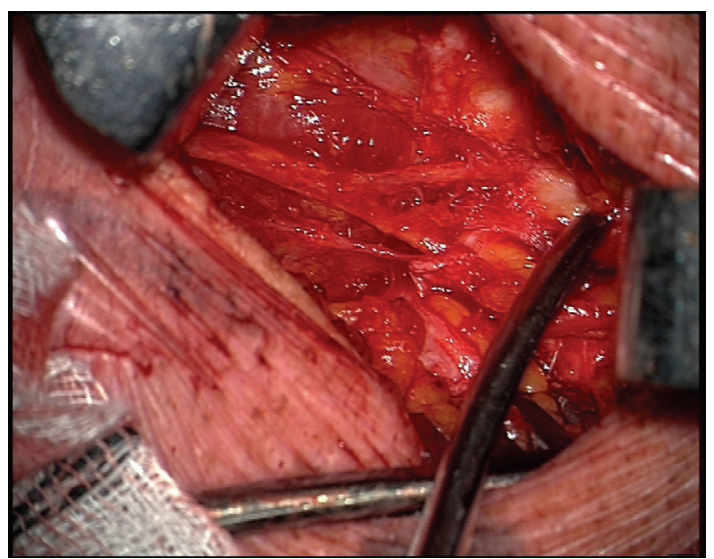

Figure 2. Thoracolumbar fascia over the nerve was released.

weeks to fully settle and the patient reported mild discomfort during this time. He was able to return to elite cricket the following season and has had no recurrence of symptoms in the area to date.

\section{Discussion}

Previous anatomical studies of the superior cluneal nerve have demonstrated that the leading edge of the thoracolumbar fascia compresses the superior cluneal nerve against the iliac crest causing symptoms [5]. Anything that increases the tension of fascia or stretches it will exacerbate symptoms and we believe that this may occur during the bowling action. A number of different bowling techniques have been identified which are based around the relative alignment of the shoulders and pelvis at back foot contact $[3,9]$. However during the period from back foot contact (BFC) to front foot contact (FFC) and then ball release (BR) certain spinal movements consistently occur regardless of differing techniques. For example the trunk rotates toward the bowling arm between BFC and FFC and from FFC to ball release the trunk is flexing [9]. We believe either by repetition or large excursion, both of these movements have the potential to irritate the SCN on the contralateral side to the bowling arm. Indeed this is consistent with the clinical presentation in our case subject who experienced pain in the distribution of the superior cluneal nerve during trunk rotation between front and back foot contact and during trunk flexion after front foot contact and delivery.

The SCN may also be susceptible to compression related to contraction of the back musculature, in particular the thoraco-lumbar erector spinae (TLES) and Latissimus Dorsi which contribute to a fibro-osseus tunnel through which the medial branch of the SCN runs [5]. There is an increasing awareness that some presentations of low back pain are asso- 
ciated with increased activity in the TLES [10]. Several studies have linked chronic low back pain with increased TLES activation and increased lumbar compressive forces [11, 12]. In our case subject the preceding history of back problems would be consistent with possible increased TLES muscle activity which may contribute to a compression of the SCN. The Latissimus Dorsi muscle has been proposed to increase tension in the superficial layer of the thoraco-lumbar fascia and assist in load transfer between the trunk and legs in weight bearing activities [13]. Considering a fast bowler has front foot impact forces from $6-8$ times their body weight during the delivery stride [3], it would be reasonable to expect high Latissimus Dorsi activation at this time. We therefore postulate that increased tone in the muscles around the SCN may also contribute to a compression of the SCN.

At the time of surgery, the medial branch was compressed by a fibrous band of tissue as it passed from beneath the fibro-osseous tunnel. The operating microscope is a useful but not essential adjunct for this procedure. This is in keeping with the findings reported by Maigne et al. in a series of surgical releases where he reported a success rate of $75 \%$ [8]. Best results were in those patients with visible changes in the nerve.

Since treating this patient we have diagnosed a further two patients with superior cluneal nerve entrapment and successfully treated it with surgical decompression. Stringent diagnostic criteria must be maintained. These include, point tenderness over the iliac spine $8 \mathrm{~cm}$ from the midline with a fan shaped distribution of pain from this point $[5,6,8]$, and a diagnostic pain free interval with infiltration of local anaesthetic into the region on at least two separate occasions. Other causes of pain about the region must be excluded.

Clinicians should be aware of this diagnosis when investigating athletes for chronic lower back pain and in particular fast bowlers who are likely to become predisposed to this problem through the nature of their bowling action. This report adds the growing body of evidence that sportsmen such as cricket bowlers, tennis players and volleyballers who engage in stretching of the lower trunk fascia and forceful contraction of the back musculature, may be at risk for developing superior cluneal nerve entrapment neuropathy.

\section{Dedication}

The authors wish to dedicate this article to the memory of Dr June Canavan - sports physician, friend and mentor - whose tenacity, talented clinical acumen and attention to detail lead to the diagnosis and successful management of many athletes, including the one presented in this manuscript. Reflecting the typical selfless dedication to others for which she was so well known, "Dr June" died in 2009 in the pursuit of helping others.

\section{References}

1. Orchard JW, James T, Portus MR. Injuries to elite male cricketers in Australia over a 10-year period. J Sci Med Sport 2006;9(6):459-467.

2. Bartlett RM, Stockill NP, Elliott BC, Burnett AF. The biomechanics of fast bowling in men's cricket: a review. J Sports Sci 1996;14(5):403-424.

3. Portus M, Mason BR, Elliott BC, Pfitzner MC, Done RP. Technique factors related to ball release speed and trunk injuries in high performance cricket fast bowlers. Sports Biomech 2004;3(2):263-284.

4. Schwarzer AC, Aprill CN, Derby R, Fortin J, Kine G, Bogduk N. The relative contributions of the disc and zygapophyseal joint in chronic low back pain. Spine (Phila Pa 1976) 1994;19(7):801-806.

5. Lu J, Ebraheim NA, Huntoon M, Heck BE, Yeasting RA. Anatomic considerations of superior cluneal nerve at posterior iliac crest region. Clin Orthop Relat Res 1998;(347):224-228.

6. Maigne JY, Maigne R, Guerin-Surville H. Upper thoracic dorsal rami: anatomic study of their medial cutaneous branches. Surg Radiol Anat 1991;13(2):109-112.

7. Aly TA, Tanaka Y, Aizawa T, Ozawa H, Kokubun S. Medial superior cluneal nerve entrapment neuropathy in teenagers: a report of two cases. Tohoku J Exp Med 2002;197(4):229-231.

8. Maigne JY, Doursounian L. Entrapment neuropathy of the medial superior cluneal nerve. Nineteen cases surgically treated, with a minimum of 2 years' follow-up. Spine (Phila Pa 1976) 1997;22(10):1156-1159.

9. Ranson CA, Burnett AF, King M, Patel N, O'Sullivan $\mathrm{PB}$. The relationship between bowling action classification and three-dimensional lower trunk motion in fast bowlers in cricket. J Sports Sci 2008;26(3):267-276.

10. O'Sullivan P. Diagnosis and classification of chronic low back pain disorders: maladaptive movement and motor control impairments as underlying mechanism. Man Ther 2005;10(4):242-255.

11. Marras WS, Davis KG, Ferguson SA, Lucas BR, Gupta P. Spine loading characteristics of patients with low back pain compared with asymptomatic individuals. Spine (Phila Pa 1976) 2001;26(23):2566-2574.

12. Ferguson SA, Marras WS, Burr DL, Davis KG, Gupta P. Differences in motor recruitment and resulting kinematics between low back pain patients and asymptomatic participants during lifting exertions. Clin Biomech (Bristol, Avon) 2004;19(10):992-999.

13. Vleeming A, Pool-Goudzwaard AL, Stoeckart R, van Wingerden JP, Snijders CJ. The posterior layer of the thoracolumbar fascia. Its function in load transfer from spine to legs. Spine (Phila Pa 1976) 1995;20(7):753758. 